\title{
THE MANUFACTURE OF ANTIBODIES IN VITRO
}

\author{
By linus Pauling, Ph.D., and DaN H. Campbell, Pr.D. \\ (From the Gates and Crellin Laboratories of Chemistry, California Institute of Technology, \\ Pasadena, California)
}

(Received for publication, April 25, 1942)

Two years ago there was published (1) a theory of the structure and process of formation of antibodies which had been developed from the available information about intramolecular and intermolecular forces. The prediction was made from this theory that antibodies could be manufactured in vitro from suitable protein molecules by use of an appropriate general method, which was described as follows:-

"An interesting possible method of producing antibodies from serum or globulin solution outside of the animal is suggested by the theory. The globulin would be treated with a denaturing agent or condition sufficiently strong to cause the chain ends to uncoil; after which this agent or condition would be removed slowly while antigen or hapten is present in the solution in considerable concentration. The chain ends would then coil up to assume the configurations stable under these conditions, which would be configurations complementary to those of the antigen or hapten."

We have during the past two years carried out experiments along these lines, and have succeeded in endowing normal serum globulin with the properties of a specific antibody; in other words, we would seem to have converted normal globulin into antibody. Similar but less satisfactory results have been obtained also with other serum proteins. Our experiments are described in the following sections of this paper., ${ }^{1,2}$

\section{Orienting Experiments with Methyl Blue as Antigen}

Many orienting experiments were carried out with the dye methyl blue as antigen. This dye as obtained commercially is a mixture of the $p$-trisulfonated and disulfonated pararosanilines, with formulas such as

${ }^{1} \mathrm{~A}$ brief statement of the results of these experiments has been published: Pauling, L., and Campbell, D. H., Science, 1942, 95, 440.

${ }^{2}$ We acknowledge with appreciation the financial support of this work by the Rockefeller Foundation. We are also indebted to Dr. David Pressman and Mr. Carol Ikeda of these Laboratories for help with the experiments, and to Dr. W. Goebel of The Rockefeller Institute for Medical Research, Dr. E. J. Cohn of Harvard Medical School, and Dr. J. D. Porsche of Armour and Co. for providing us with materials. 


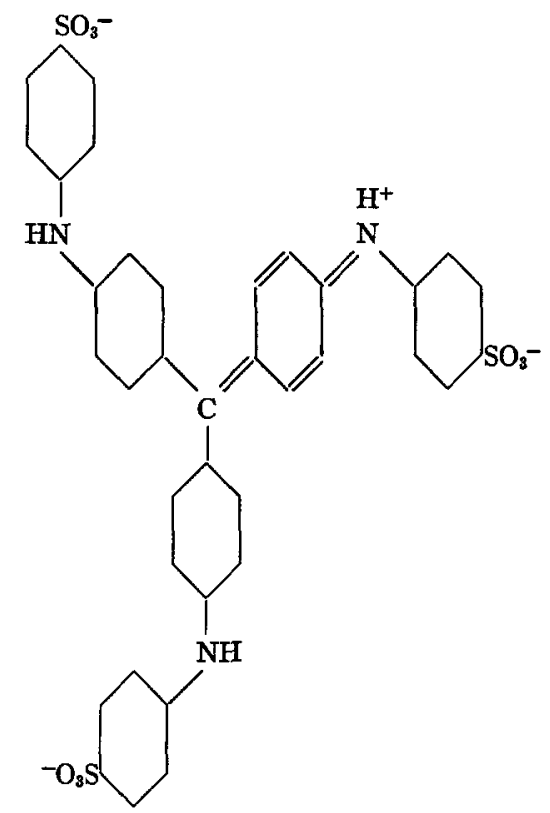

It was selected because of its high solubility in water, its intense color (giving increased accuracy to colorimetric analyses), its dialyzability, and the presence in the molecule of strong haptenic groups. The protein used for most of the preliminary experiments was a $\gamma$-globulin fraction obtained by essentially the methods employed by Hewitt (2) and by Cohn and collaborators (3) in their studies of serum proteins. It was the protein fraction from fresh beef serum which is insoluble at 33 per cent saturation with ammonium sulfate. The material was reprecipitated once, washed with salt solution, and then dialyzed free of ammonium sulfate at $\mathrm{pH} 7.5$ and $4^{\circ} \mathrm{C}$. The resulting solution was then stored in the refrigerator until used.

Of the five methods of denaturation used in the preliminary investigations, treatment with sodium hydroxide solutions gave the most promising results. A typical experiment was carried out as follows:-

Enough dye was added to a 2.0 per cent protein solution to give a dye concentration of 0.1 per cent and enough $0.1 \mathrm{~N} \mathrm{NaOH}$ to raise the $\mathrm{pH}$ to approximately 11.0. After the mixture had stood for 15 to 30 minutes, a $10.0 \mathrm{ml}$. sample was removed, placed in a cellophane bag, and dialyzed at $4^{\circ} \mathrm{C}$. against a stream of phosphate buffer of pH 7.5. In this way the protein molecules, which had been subjected to the denaturing action of the alkali, were given the opportunity of changing slowly to configurations stable in neutral solution and in the presence of the antigen. The renaturing process took place over a period of several hours, during which the $\mathrm{pH}$ of the protein-antigen solution changed slowly from 11.0 to 7.5. At this point a small amount of proteindye precipitate had appeared. On continued dialysis, with loss of dye, the amount of 
precipitate increased. At the end of 24 hours only a small amount of dye remained in solution, the rest having been precipitated or dialyzed through the cellophane. The dialysis was continued for 72 hours, at the end of which only a trace of dye remained in solution.

Various control experiments were made, such as the following. A $10 \mathrm{ml}$ sample of the dye-protein-alkali solution which had stood at $\mathrm{pH} 11.0$ for 15 to 30 minutes was brought to $\mathrm{pH} 7.5$ very rapidly by addition of $0.1 \mathrm{~N} \mathrm{HCl}$ solution, and was then dialyzed as above. A second control experiment was made with no addition of alkali; the dye-protein solution at $\mathrm{pH} 7.5$ was dialyzed. In both of the controls only a trace of dye remained in solution after dialysis.

The precipitates were dissolved in dilute $\mathrm{NaOH}$ solution and analyzed for dye colorimetrically and for protein by Kjeldahl nitrogen determination. A large amount of precipitate was formed both in the main experiment (with slow neutralization) and in the first control; however, the precipitate from the main experiment contained $80 \mu \mathrm{g}$. of dye per mg. protein, and that from the first control only 6 . Only a small amount of precipitate, with $3 \mu \mathrm{g}$. of dye per mg. protein, was obtained in the second control. The precipitate from the main experiment was soluble in excess dye and in sodium $p$-sulfanilate solution (hapten), but not in other unrelated dyes or hapten solutions, such as sodium $p$-arsanilate solution. The control precipitates were insoluble or only slightly soluble under these conditions.

These facts indicate that the precipitate obtained by slow removal of the denaturing agent (hydroxide ion) is a specific antigen-antibody precipitate, that obtained in the first control being denatured protein and that obtained in small quantity in the second control being non-specific dye-protein complex.

Various methods were tried, without success, to separate the dye from the dye-protein precipitate and to obtain a specific precipitin for the dye. Methods used consisted of treating the dye-protein precipitate with acid and alkaline solutions, strong salt solution (20 per cent $\mathrm{NaCl}$ ), and dialysis against solution of hapten ( $p$-sulfanilate ion). The precipitate dissolved in relatively strong alkaline solutions and the dye could then be removed by dialysis but the resulting protein had lost its affinity for dye. The precipitate did not dissolve in acid or strong salt solutions nor was the dye removed by dialysis against these solutions. Some of the precipitate dissolved in $0.01 \mathrm{~N}$ hapten solution but the dye was not removed by dialysis against this solution. Our later experience with arsanilate indicates that this failure was due to the use of too low hapten concentration.

Other methods of denaturation gave varying results. Heat denaturation at various temperatures up to $80^{\circ} \mathrm{C}$. with slow cooling produced approximately the same effect as alkali denaturation. Acid treatment at $\mathrm{pH} 2.5$ led to no alteration in affinity for dye. Although $3.5 \mathrm{~N}$ urea solutions produced considerable denaturation, there was no evidence of increased affinity for dye. Surface denaturation brought about by long continued shaking of a 1 per cent protein solution in the presence of dye gave a precipitate containing approximately $200 \mu \mathrm{g}$. of dye per mg. of protein. However, the precipitate formed 
by this method was not soluble in excess dye or in hapten solution, and hence in this respect is not closely similar to an antigen-antibody precipitate. We think that surface denaturation can probably also be developed into a satisfactory method of in vitro manufacture of antibodies.

Although most of the investigations were carried out with the $\gamma$-globulin fraction, alkali denaturation tests were also made with other serum fractions obtained by salt precipitation. All of these fractions, including serum albumin, showed on treatment an increase in dye affinity, somewhat smaller than that shown by the $\gamma$-globulin fraction.

The Manufacture of Antibodies Homologous to the Azophenylarsonic Acid Group

In other experiments which led to the preparation of protein solutions with properties of specific antisera a different method of causing the change in configuration of the protein molecules was used; namely, increased thermal agitation at a temperature lower than that which leads to precipitation of denatured protein. At a temperature just below the "denaturation temperature" (at which precipitation occurs) the protein molecules would be expected to assume various configurations and to change more easily from one configuration to another than at room or body temperatures. It was accordingly expected that under these conditions the protein in the presence of antigen would change from its normally stable configuration to configurations stable in the presence of antigen molecules, namely, those complementary to active parts of the antigen molecules.

This method was carried out with another dye, 1,3-dihydroxy-2,4,6,tri( $p$-azophenylarsonic acid)benzene, which had been found (4) to give very good precipitates with hapten-homologous rabbit antiserum. This dye, which contains three azophenylarsonic acid groups attached to a resorcinol molecule, has the following formula:-

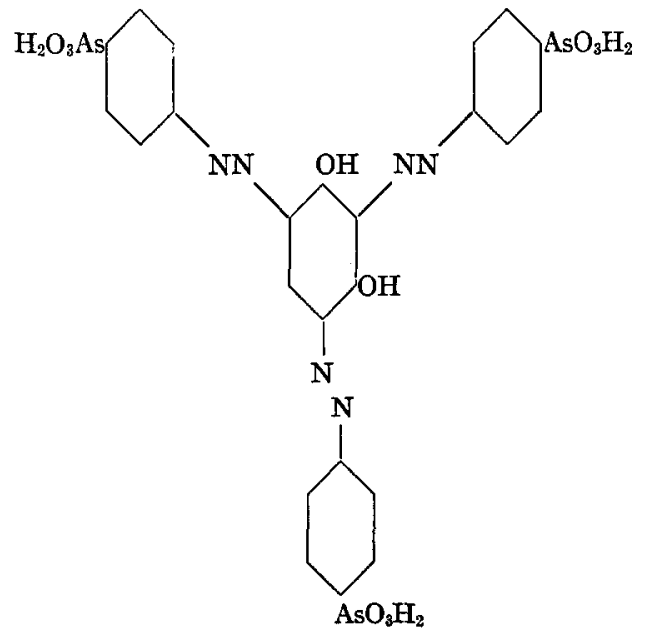


It dialyzes through cellophane, and its color is intense enough to permit accurate colorimetric analyses to be made.

The $\gamma$-globulin used in these experiments was prepared from fresh beef plasma by ethanol precipitation as described by Cohn and collaborators (5). At first the experiments were carried out with material prepared in our laboratory, and the later work was done with preparations kindly supplied through the courtesy of Dr. E. J. Cohn of Harvard Medical School and Dr. J. D. Porsche of Armour and Co. No significant difference in behavior was observed between the two preparations.

Preparation of the modified protein was carried out as follows:-

A solution containing 0.01 per cent of dye and 1.0 per cent of protein at approximately $\mathrm{pH} 7.8$ was placed in a water bath at $57^{\circ} \mathrm{C}$., which is about $10^{\circ}$ below the denaturation temperature of the protein. At the end of 3 or 4 days, depending upon temperature, concentration of reagents, and $\mathrm{pH}$, precipitate began to appear. The amount of precipitate increased for several days. After 11 to 14 days the mixture was removed from the bath, placed in a cellophane bag, and dialyzed for 24 hours against 1.0 per cent $\mathrm{NaCl}$ solution to remove most of the free dye. Some additional precipitation occurred during this process. The material was then placed in a fresh bag and dialyzed until no more dye was removed against $0.5 \mathrm{~N}$ arsanilate solution, made by dissolving arsanilic acid ( $p$-aminophenylarsonic acid, $\mathrm{H}_{2} \mathrm{NC}_{6} \mathrm{H}_{4} \mathrm{AsO}_{3} \mathrm{H}_{2}$ ) in sodium hydroxide solution and bringing to the desired $\mathrm{pH}, 7.5$. This required about 4 days, during which the solution was continually agitated and the hapten solution, the volume of which was five times that of the protein solution, was changed every 24 hours. Most of the precipitate dissolved during this hapten dialysis; the insoluble protein material which remained was discarded and the solution was then dialyzed against 1.0 per cent $\mathrm{NaCl}$ solution until free of hapten. This required 3 to 4 days. If all of the dye had not been removed by treatment with hapten, precipitation occurred as soon as the hapten concentration was reduced by saline dialysis, and the foregoing process had then to be repeated.

The final solution prepared by this method was clear and contained approximately 40 per cent of the original protein and no dye. The modified protein, which will subsequently be referred to as manufactured antibody, behaved like natural antibody in forming specific precipitates and in the fixation of complement. It was specific in that it reacted with homologous antigens; namely, many of the simple phenylarsonic acid azo dyes and azoproteins, but failed to react with similar sulfanilic antigens. Furthermore, preparations of $\gamma$-globulin which had been treated in a similar manner but in the absence of dye also failed to show any activity.

Precipitin tests using the trisubstituted resorcinol dye as test antigen gave typical optimum proportion zones, with no precipitate forming in excess antigen or in the presence of homologous hapten such as sodium arsanilate. The precipitates which formed with both simple dyes and azoproteins showed the same low solubility as natural antibody precipitates. For example, there 
was no appreciable loss of antigen or antibody after the third washing with buffer solution, and diluted antigen-antibody mixtures gave the same amounts of precipitate as undiluted mixtures. However, the reactions differed from those of immune sera in that more critical conditions were necessary for precipitation. For example, the manufactured antibody was found to give no precipitate with antigen at $\mathrm{pH}$ values greater than 6.5 or with $\mathrm{NaCl}$ concentration over 4 per cent, although formation of soluble complexes of antibody and antigen was shown to have occurred by the failure of the dye antigen to dialyze out of the solution. Another apparent difference was that with increase in $\mathrm{pH}$ the optimum proportion zone was found to shift to a higher antibody/antigen ratio. These characteristics are presumably due to the particular method of preparation used.

Precipitin tests were carried out as follows:-

To 1.0 mi. portions of manufactured antibody solution containing acetate buffer there were added equal volumes of various dye dilutions which were also buffered with acetate. The mixtures were allowed to stand for 24 hours at room temperature, and the precipitates were then washed three times with buffer solution and analyzed for dye colorimetrically and for total nitrogen by micro Kjeldahl. The antibody nitrogen in the precipitate was then obtained as the difference between total and dye nitrogen. The same methods were employed for the azoprotein antigens.

The results obtained with the trisubstituted resorcinol dye at $\mathrm{pH} \mathbf{5 . 0}$ and 5.5 are given in Table I. The amount of manufactured antibody was kept constant $(4.10 \mathrm{mg}$.) and the amount of dye was varied from $5.280 \mathrm{mg}$. to $0.020 \mathrm{mg}$. At $\mathrm{pH} 5.0$ the equivalence zone occurred at $1.320 \mathrm{mg}$. of dye and at $\mathrm{pH} 5.5$ the zone shifted to $0.330 \mathrm{mg}$. However, the equivalence zone for a given $\mathrm{pH}$ occurred at a constant total antibody/antigen ratio over a wide range of antibody dilutions. The molecular ratio of antibody to antigen in the precipitates was much smaller than is ordinarily obtained with natural antibody, but several factors make the significance of the values doubtful. Of these the most important is that there is a tendency for this dye to associate in the lower $\mathrm{pH}$ range. There is also the possibility that the valence of the antibody formed under these conditions differs from that formed under natural conditions due to the randomness of the structural changes which take place during denaturation. The titer of this particular preparation of manufactured antibody expressed in terms of limiting dilutions was 1:200,000.

It will be noted from Table I that under the best conditions only about 15 per cent of the manufactured antibody was precipitated. However, we might well expect that the methods described above would produce a very heterogeneous mixture of protein structures varying from unchanged molecules and univalent antibodies to antibodies with several combining regions. A more active preparation with about 80 per cent of the protein precipitable could be 
TABLE I

Data for Precipitation Reactions of Phenylarsonic Acid Azodye and Manufactured Antibody

\begin{tabular}{|c|c|c|c|c|c|}
\hline \multirow[b]{2}{*}{ Tube No. } & \multirow[b]{2}{*}{$\begin{array}{l}\text { Amount of } \\
\text { antibody used }\end{array}$} & \multirow[b]{2}{*}{$\begin{array}{l}\text { Amount of } \\
\text { antigen used }\end{array}$} & \multicolumn{3}{|c|}{ Composition of precipitate } \\
\hline & & & Amount of dye & $\begin{array}{l}\text { Amount of } \\
\text { antibody }\end{array}$ & $\begin{array}{l}\text { Molecular } \\
\text { ratio antibody/ } \\
\text { antigen }\end{array}$ \\
\hline & $m g$ & mg. & $m g$. & $m g$. & \\
\hline \multicolumn{6}{|l|}{ pH 5.0} \\
\hline 1 & 4.10 & 5.280 & 0.106 & 0.387 & 0.020 \\
\hline 2 & “ & 2.640 & 0.111 & 0.591 & 0.027 \\
\hline 3 & “ & 1.320 & 0.120 & 0.617 & 0.026 \\
\hline 4 & 6 & 0.660 & 0.099 & 0.548 & 0.029 \\
\hline 5 & 6 & 0.330 & 0.077 & 0.465 & 0.032 \\
\hline 6 & 6 & 0.165 & 0.048 & 0.362 & 0.039 \\
\hline 7 & 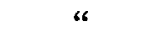 & 0.082 & 0.027 & 0.248 & 0.048 \\
\hline 8 & “ & 0.041 & 0.021 & 0.158 & 0.039 \\
\hline 9 & 6 & 0.020 & 0.016 & 0.135 & 0.045 \\
\hline \multicolumn{6}{|l|}{$\mathrm{pH} 5.5$} \\
\hline 1 & “ & 5.280 & 0.022 & 0.070 & 0.016 \\
\hline 2 & $" 6$ & 2.640 & 0.047 & 0.169 & 0.018 \\
\hline 3 & $" 6$ & 1.320 & 0.053 & 0.232 & 0.022 \\
\hline 4 & 6 & 0.660 & 0.054 & 0.259 & 0.024 \\
\hline 5 & $" 6$ & 0.330 & 0.039 & 0.304 & 0.040 \\
\hline 6 & $"$ & 0.165 & 0.032 & 0.190 & 0.030 \\
\hline 7 & 6 & 0.082 & 0.021 & 0.156 & 0.038 \\
\hline 8 & 6 & 0.041 & 0.009 & 0.089 & 0.050 \\
\hline 9 & " & 0.020 & 0.009 & 0.056 & 0.032 \\
\hline
\end{tabular}

TABLE II

Data for Precipitation Reactions of Phenylarsonic Acid Azo-Ovalbumin and Manufactured Antibody

\begin{tabular}{|c|c|c|c|c|c|}
\hline \multirow[b]{2}{*}{ Tube No. } & \multirow{2}{*}{$\begin{array}{l}\text { Amount of } \\
\text { antibody used }\end{array}$} & \multirow{2}{*}{$\begin{array}{c}\text { Amount of } \\
\text { antigen used }\end{array}$} & \multicolumn{3}{|c|}{ Composition of precipitate } \\
\hline & & & $\begin{array}{l}\text { Amount of } \\
\text { antigen }\end{array}$ & $\begin{array}{l}\text { Amount of } \\
\text { antibody }\end{array}$ & $\begin{array}{l}\text { Molecular } \\
\text { ratio antibody } / \\
\text { antigen }\end{array}$ \\
\hline & $m g$. & $\mathrm{mg}$. & mg. & mg. & \\
\hline \multicolumn{6}{|l|}{ pH 5.5} \\
\hline 1 & 4.10 & 6.530 & 0.318 & 0.570 & 0.67 \\
\hline 2 & “ & 3.265 & 0.256 & 0.420 & 0.62 \\
\hline 3 & “ & 1.632 & 0.219 & 0.407 & 0.71 \\
\hline 4 & " & 0.816 & 0.212 & 0.362 & 0.65 \\
\hline 5 & “ & 0.408 & 0.100 & 0.320 & 1.22 \\
\hline 6 & “ & 0.204 & 0.068 & 0.212 & 1.18 \\
\hline 7 & “ & 0.102 & 0.043 & 0.162 & 1.43 \\
\hline 8 & 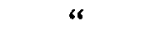 & 0.051 & 0.043 & 0.137 & 1.21 \\
\hline
\end{tabular}


obtained by extracting only the dye-protein precipitate which formed during the initital dialysis against saline, but the yields have been so small that very little work has been done with such preparations. It will also be noted that only about 15 per cent of the dye antigen was precipitated under optimum conditions, which agrees closely with results obtained with the same dye and natural antibodies.

The manufactured antibody solution was found to precipitate azoprotein. Reactions with phenylarsonic acid azo-ovalbumin (Table II) were observed to be somewhat different from those with the simple dye antigen in that under the conditions studied so far no optimum zone has been obtained with respect to change in $\mathrm{pH}$ or antibody dilutions. The antigen used was prepared by coupling the diazonium salt of arsanilic acid in the usual manner to crystalline ovalbumin. The resulting product analyzed 74 hapten groups per molecule of protein. Within the range studied, the amount of manufactured antibody protein precipitated was of the same order as that found in the simple dyeantibody precipitates. However, the amount of antigen was much less, and the antibody/antigen ratios are similar to those obtained in precipitates with natural antibody. For example, in the region approximating antigen excess the ratio is 0.67 and in the region of antibody excess the ratio became slightly higher than one.

\section{Experiments on the Manufacture of Antibodies to Pneumococcus Polysaccharide Type III}

Similar experiments were also carried out with pneumococcus polysaccharide Type III as antigen.

$1 \mathrm{gm}$. of pneumococcus polysaccharide Type III was kindly sent to us by Dr. Walther Goebel of The Rockefeller Institute for Medical Research. This was used with $\gamma$-globulin in the same way as the azoresorcinol antigen. 25 $\mathrm{ml}$. of 1 per cent $\gamma$-globulin solution was taken, and $250 \mathrm{mg}$. of the polysaccharide was dissolved in it, a little alkali also being added, since the polysaccharide was in the form of an acid. The final $\mathrm{pH}$ was adjusted to 7.5. The mixture was then kept for 2 weeks at $57^{\circ}$ in a thermostat. At the end of this time a small amount of precipitate had been formed. The mixture was removed from the bath and the solution separated from the precipitate. It was found that when a small amount of polysaccharide solution was added to a portion of the supernatant solution a precipitate was formed. This was presumably an antigen-antibody precipitate, indicating that in the original solution there was an excess of antibody. This precipitate was found to contain both protein and polysaccharide; the protein was shown to be present by the biuret test and the polysaccharide by dissolving it in dilute alkali and adding calcium hydroxide, which produced a precipitate of the calcium salt of the polysaccha- 
ride. Both protein and polysaccharide were also shown to be present in the precipitate originally produced during the 2 weeks' heating.

The specificity of the supernatant solution was shown by the fact that it did not precipitate with Type I polysaccharide solution. The Type VIII polysaccharide also did not give a precipitate, despite the fact that it contains the same groups as the Type III polysaccharide; this may have been due to weakness of the artificial antiserum.

Agglutination tests were also carried out with the original supernatant solution. It was found that this solution agglutinated Type III pneumococci but did not agglutinate either Type I or Type II pneumococci.

The attempt was then made to prepare a pure preparation, by separating the polysaccharide from the protein solutions. This was tried in two ways. The first method tried consisted in adding sodium chloride to about 15 per cent concentration, and then adding hydrochloric acid to about $\mathrm{pH} 4$, at which point the polysaccharide precipitated. It was removed, and the solution dialyzed against physiological saline and the $\mathrm{pH}$ adjusted to 7 . The solution obtained in this way was found to have only slight activity. It gave a very slight precipitate with solution of Type III polysaccharide only in a very narrow concentration zone. This zone was in the region of a tenth of a milligram of polysaccharide per milliliter of undiluted antibody solution. Polysaccharide Type I did not give any reaction with this antibody solution.

The other preparation was made by adding 15 per cent salt, and then calcium hydroxide and calcium chloride, which precipitates the polysaccharide. The $\mathrm{pH}$ was about 9 after this treatment. The resulting solution was found to give a small amount of precipitate with polysaccharide Type III in a narrow concentration zone. The reaction was somewhat stronger than that given by the solution made by the acid precipitation method.

Agglutination tests were carried out with these purified antibody solutions. The solution from the acid precipitation did not give definite agglutination. That from the calcium precipitation gave definite, though not strong, agglutination with Type III pneumococci. The agglutination was not complete enough to cause all the pneumococci to form a single clump but was enough to cause many small clumps to form. The agglutination could be achieved still after two twofold dilutions of the original purified antibody solution, which contained about $3 \mathrm{mg}$. of protein per milliliter. The fact that agglutination did not occur after further dilution shows that the agglutinin solution is very weak. Agglutination could not be detected with either Type I or Type II pneumococci.

It seems likely, from the low titer of the agglutinin in the purified antibody solution, that the artificial antibody was largely destroyed by the process of purification. Probably the most active fraction was carried down with the polysaccharide during its precipitation. 
SUMMARY

A protein solution with the properties of a specific antiserum to the triphenylmethane dye methyl blue has been made by treating a solution of bovine $\gamma$-globulin and the dye with alkali and then slowly neutralizing the alkali. Some success has been obtained also in the formation of antibodies from other serum proteins and by other denaturation-renaturation procedures.

By heating solutions of $\gamma$-globulin and antigen to $57^{\circ} \mathrm{C}$. for several days antisera homologous to the antigens have been prepared. This method has been used successfully with the azodye 1,3-dihydroxy-2,4,6-tri( $p$-azophenylarsonic acid)benzene and with pneumococcus polysaccharide Type III. The antipneumococcus sera were found to precipitate the polysaccharide of Type III but not those of Types I and VIII and to agglutinate pneumococci of Type III but not those of Types I and II.

\section{BIBLIOGRAPHY}

1. Pauling, L., J. Am. Chem. Soc., 1940, 62, 2643.

2. Hewitt, L. F., Biochem. J., 1934, 28, 2080; 1936, 30, 2229; 1937, 31, 360.

3. Cohn, E. J., McMeekin, T. L., Oncley, J. L., Newell, J. M., and Hughes, W. L., J. Am. Chem. Soc., 1940, 62, 3386.

4. Pauling, L., Pressman, D., Campbell, D. H., Ikeda, C., and Ikawa, M., J. Am. Chem. Soc., to be published.

5. Cohn, E. J., Luetscher, J. A., Jr., Oncley, J. L., Armstrong, S. H., Jr., and Davis, B. D., J. Am. Chem. Soc., 1940, 62, 3396. 